\title{
FERRO-CARRILES Y TRANSFORMACIÓN URBANA EN BARCELONA
}

\author{
Enrique Viana Suberviola \\ Universidad de Barcelona \\ enriviana@gmail.com
}

\section{RESUMEN}

En general, el impacto de los sistemas ferro-viarios es muy positivo en cuanto a la mejora de la accesibilidad de un área, a la renovación urbanística y a la conectividad del conjunto del sistema. Normalmente se procura la interconexión de las infraestructuras ferro-viarias para provocar sinergias entre ellas y maximizar su uso. Pero las redes ferro-viarias también jerarquizan el territorio. Por ello, es importante reconducir el desarrollo ferro-viario hacia modelos reticulares que abarquen la máxima superficie del terreno homogéneamente y procurando favorecer el policentrismo urbano e intraurbano.

Palabras clave: ferro-carril, transformaciones territoriales, sinergias, urbanismo.

\section{ABSTRACT}

In general, the impact of railway network is very positive, in terms of the improvement of the accessibility of an area, the urban renewal and the connectivity of the entire system. Normally it seeks the interconnection of railway infrastructure to cause synergies among them and maximize its use. But the railway networks not nest the territory too. Therefore, it is important, that railway development is reticular and encompassing the maximum area of land, in a homogeneous way, and trying to encourage the polycentrism, the urban and the intra-urban.

Keywords: railway, territorial transformation, synergies, urbanism.

Fecha de recepción: julio 2015.

Fecha de aceptación: marzo 2016. 


\section{INTRODUCCIÓN}

El desarrollo urbano y los transportes han tenido evoluciones paralelas. Se han influido mutuamente, en ocasiones difuminándose totalmente la causa y el efecto de uno y otro. La planificación territorial actual tiene en cuenta el desarrollo conjunto de ambos sistemas porque es consciente de la interrelación mutua que existe y de la importancia del correcto desarrollo de uno de los sistemas, para la expansión y fortalecimiento del otro. Pero esta connotación es un fenómeno relativamente actual. Hay que tener en cuenta que, hasta el siglo XIX, las ciudades poseían una determinada estructura en función de las distancias que estaban dispuestos a recorrer sobre todo a pie sus habitantes.

Posteriormente, con la incorporación de los medios de transporte mecánicos, esa situación se modificó paulatinamente. Hasta la Segunda Guerra Mundial, fueron predominantes los medios de transporte colectivos, pero, más tarde, comenzó el auge del automóvil privado que intensificó la descentralización de las actividades, especialmente la residencial, lo que provocó la aparición de las ciudades satélites. Este hecho ocasionó una progresiva pérdida diferencial de la densidad urbana y esta dispersión provocó la aparición de las áreas metropolitanas, que conformaban espacios, que segregaban las áreas residenciales de las áreas de actividad secundaria y terciaria (fordismo). Pero esta situación se revirtió, ya que, posteriormente, el transporte colectivo recobró un nuevo auge al ser percibido como más sostenible y económico (postfordismo).

Actualmente se conoce la cantidad de efectos inducidos por un medio de transporte en un área urbana. Los efectos que producen los transportes en la ciudad son varios y son responsables, en buena medida, de la configuración urbana. Los transportes modifican la forma de la ciudad creando polos de atracción alrededor de las estaciones y vías que generan cambios en los usos y el valor del suelo. El transporte reduce las distancias e impulsa la movilidad, dinamizando así las actividades productivas. Sin embargo, el aumento de accesibilidad de unas áreas provoca el mayor aislamiento de otras, jerarquizando el territorio y provocando un efecto barrera.

La configuración de las redes y líneas de transporte resultan, pues, vitales para entender el desarrollo urbano y la sociedad en su conjunto.

\section{OBJETIVOS, METODOLOGÍA Y FUENTES}

El objetivo de este trabajo es poder confirmar empíricamente en Barcelona y su área metropolitana la interrelación existente entre sistema urbano y redes de transporte y sin duda, algunas de las redes de transporte más importantes son las redes ferro-viarias. Se consideran ferro-viarios, según una denominación decimonónica, como indica H. Capel (2011, p. 11) a todos aquellos medios de transporte que usan de vías férreas para su desplazamiento. Dentro de esta categoría se incluiría siguiendo un orden relacionado con su aparición histórica al ferrocarril, al tranvía, al funicular, al metro, al metro ligero y al tren de alta velocidad.

El ámbito de análisis estudiado es el área metropolitana de Barcelona. Para los diferentes períodos históricos analizados existen ámbitos territoriales diferenciados. Es decir, se analiza en cada período histórico la totalidad de los municipios metropolitanos de Barcelona que 
dispongan dentro de sus límites municipales de algún tipo de sistema ferro-viario urbano (metro, tranvía, metro ligero, funicular). Por lo tanto, el ámbito espacial de análisis viene determinado por los siguientes municipios: Barcelona, l'Hospitalet de Llobregat, Esplugues de Llobregat, Cornellà de Llobregat, Santa Coloma de Gramenet, Badalona, Sant Adrià de Besòs, el Prat de Llobregat, Sant Boi de Llobregat, Montcada i Reixac, Sant Just Desvern, Sant Joan Despí, Sant Feliu de Llobregat, Molins de Rei y Sant Vicenç dels Horts.

Para comprobar la relación urbe-ferro-carril en dicho ámbito se ha procedido a realizar tres tipos de análisis territoriales. El primero de ellos compara las pautas de distribución de los equipamientos en un área urbana y su relación con las redes ferro-viarias. La información cartográfica y alfanumérica necesaria para dicho análisis se consiguió digitalizando miles de equipamientos y servicios de la Guia de carrers de l'àrea metropolitana de Barcelona de 2007 cedida por A.M.B. También se hizo uso de las capas de usos del suelo obtenidas en el Pla Territorial Metropolità de Barcelona de 2010.

El segundo análisis compara los centroides de las áreas urbanas estudiadas y los centroides resultantes de la fusión de los ámbitos de influencia de cada estación ferro-viaria (calculada en todo a 500 metro alrededor de cada una de ellas). La cercanía o lejanía de ambos centroides indicará una mayor o menor correlación entre el área urbana y la red ferro-viaria. Uno de los objetivos de este análisis es el de comprobar la existencia de la localización espacial ambiental común (cuando dos o más elementos coinciden en un mismo espacio por causas ambientales comunes aunque exista o no vinculación entre los diversos elementos entre sí).

El tercer análisis compara la evolución de las redes ferro-viarias con la evolución del precio de la vivienda. Se ha utilizado para dicho análisis los datos relativos a la evolución del precio de la vivienda existente en la tesis de Pasqual Maragall (defendida en 1978 y publicada al año siguiente).

Para la realización del trabajo se utilizaron diversas fuentes cartográficas y estadísticas y diferentes programas informáticos. Las principales fuentes fueron la base gráfica ferro-viaria cedida por A.T.M (Autoritat del Transport Metropolità) y las bases cartográficas cedidas por A.M.B (Ámbit Metropolità de Barcelona).

Por último, cabe señalar que los programas informáticos utilizados para tratar los datos obtenidos fueron el programa de generación cartográfica Arc Gis 9.3 y los programas de gestión de base de datos Access y Excel.

\section{ANTECEDENTES}

\section{III.1. Aspectos generales de la relación entre territorio y ferro-carril}

El estudio de la influencia de las comunicaciones en el territorio tiene ancladas sus raíces desde hace décadas (Buchanan, 1972; Mumford, 1966; Vallès Ferrer y Hap Dubois, 1978). En los trabajos que emanan de este estudio se percibían las infraestructuras como las posibilitadoras del cambio y de la transformación urbana y a su vez dicha transformación urbana era el acicate que permitía la expansión y diversificación de las infraestructuras.

Las transformaciones urbanas se han ido desarrollando de forma creciente desde el siglo XIX (Alegret y Cabré, 2008; Asensio, 2000; García Catalá, 2010; Herce Vallejo 
y Miró Farrerons, 2002; Solá-Morales i Rubió, 1997). Son varios los factores que han posibilitado que las ciudades creciesen más allá de los $10 \mathrm{~km}$ de diámetro que poseían las ciudades más grandes del mundo antes del 1800. Algunos de esos factores tienen su origen en la demografía (la mejora de las condiciones higiénicas provocó un aumento de la natalidad y se produjo un auge demográfico, además de los efectos del constante proceso inmigratorio) y en la economía (las economías de escala tienden a aglomerarse en un espacio compacto como las grandes urbes), pero el factor que posibilitó que dicho crecimiento urbano se produjese a tal escala (actualmente hay megalópolis que sobrepasan el tamaño medio de algunas regiones europeas) fue la diversificación y proliferación de las infraestructuras de transporte.

Dentro del universo de las infraestructuras destaca sobre las demás la influencia de los sistemas ferro-viarios (según una denominación decimonónica, los ferro-carriles son aquellas infraestructuras que se desplazan por carriles de hierro, lo que incluye al ferrocarril, el metro, el tranvía, el funicular, el metro ligero, la alta velocidad...) que ha sido determinante a la hora de comprender las metamorfosis que ha experimentado el espacio urbano (Bellet, Alonso y Casellas, 2010; Capel, 2011; Febrés y Miserachs, 1991; Jiménez García, 1986; Julià, 2005; Parcerisa y Rubert de Ventòs, 2001; Seguí Pons y Petrus Bey, 1991), especialmente en el siglo XIX, ya que posteriormente las autopistas fueron las mayores impulsoras del desarrollo urbano y suburbano durante el siglo XX.

El presente artículo trata concretamente de la influencia de los sistemas ferro-viarios en una ciudad de especiales características como es Barcelona. Barcelona es una ciudad que tiene serios limitantes geográficos (ríos Besòs y Llobregat, sierra de Collserola, mar Mediterráneo) que impiden su expansión urbana y limitan su transformación ( Aguirre y Marmolejo 2010, Alcalá 2006, Bernat 2004, Busquets 1992, Candel y Casaminas 1994, García Martínez 2009, Gómez Gamboa 2011, Lluch 1972, Maragall 1979, Pascual Peaguda 2009, Roca i Cladera 1986 ). Por ello, la influencia de los transportes en la ciudad condal ha sido muy notoria ya que el espacio afectado tenía unos límites físicos muy claros y cada transformación o ampliación de los sistemas de transporte comportaba un cambio social, económico e incluso político en el área afectada (Alcaide 2005, Alemany y Mestre 1986, Miralles 1996).

El presente artículo tratará de desenmarañar algunos de los impactos más notorios que los sistemas de transporte ferro-viarios han provocado en dicha ciudad.

\section{III.2. La evolución ferro-viaria y urbana de Barcelona}

Como explica R. Alcaide González (2010), en 1848 se inauguró la segunda línea de ferrocarril española (después de la línea La Habana-Güines) y la primera de la España peninsular, que realizaba un trayecto entre Barcelona y Mataró. En ese momento, la ciudad de Barcelona se hallaba amurallada y existía un enorme hacinamiento de la población intramuros. Por ello, las primeras estaciones del ferrocarril se situaron extramuros debido a la existencia de esta barrera y al hecho de no existir dentro de la ciudad amurallada espacio suficiente para albergar este tipo de instalaciones. Un elemento de gran influencia en la disposición de estas primeras líneas, estaciones e instalaciones de ferrocarril fue la Ciudadela.

Es conveniente indicar que las infraestructuras en Barcelona transcurren por un espacio muy concreto debido a las limitaciones y condicionantes del terreno. El llano litoral, la 
depresión prelitoral y los valles de los ríos Besòs y Llobregat determinan, en buena medida, el desarrollo de infraestructuras. Estas se disponían de forma radial en torno a Barcelona y la implantación del ferrocarril ayudó a fortalecer esta disposición.

Las líneas más importantes tenían como origen Barcelona y como destino Mataró (con dirección a Francia), a Martorell (con dirección a Tarragona y Valencia), a Granollers (con dirección a Girona y Francia) y a Terrassa (con dirección a Lleida). Las líneas de Granollers y Martorell, concretamente, atravesaron el llano barcelonés, por entonces sin urbanizar, de la manera más satisfactoria para las empresas ferroviarias.

En 1854 se derribaron las murallas de Barcelona y en 1858 se eliminó la consideración de la ciudad como plaza fuerte militar (El Bando municipal que comunica a los barceloneses la voluntad de derruir las murallas es de 27 de junio de 1843). A partir de ese momento, el llano barcelonés comenzó a urbanizarse. A pesar de que este terreno era mucho mayor al de la ciudad ya constituida, el hecho de que dicho llano estuviese atravesado por multitud de líneas férreas condicionaba el futuro desarrollo urbano. Debido a este hecho (Salas, 2001) los proyectos de ensanche de Barcelona debían incluir dichas líneas ferroviarias en sus diseños. En esta época, concretamente en 1859, Ildefonso Cerdá diseñó su Plan de Ensanche, en el cual las vías ferroviarias estaban integradas en el conjunto del entramado viario. Sin embargo, la construcción del Ensanche no se realizó tal y como Cerdá lo diseñó ya que las empresas privadas modificaron dicho proyecto en función de sus intereses especulativos.

Posteriormente, en el proyecto de Docks de 1863, Cerdá consiguió eliminar aquellas dificultades que el ferrocarril infligía a la circulación viaria (Capel, 2011). Este proyecto proyectaba una red ferroviaria soterrada que atravesaba la ciudad en diversas direcciones e incluía una ronda ferroviaria que servía de interconector con todas las estaciones de ferrocarril. Al mismo tiempo, se propuso ampliar los muelles de la ciudad y vincularlos con la red ferroviaria para crear una red interna que diese servicio al puerto al tiempo que lo conectaba con las estaciones de ferrocarril más próximas (Delgado Viñas, 2010). A pesar del correcto diseño del Plan de Docks, éste nunca se llevó a cabo. Por ello, las vías férreas presentes en el llano barcelonés continuaron siendo un obstáculo para su urbanización.

La construcción de las líneas ferroviarias estuvo marcada por las fluctuaciones derivadas de las diversas fusiones empresariales que se fueron sucediendo y por las trabas administrativas (en todo caso, el derribo de las murallas, de la Ciudadela y la construcción de las líneas ferroviarias propició la creación de puestos de trabajo). Las compañías ferroviarias actuaban según sus intereses particulares, sin tener en cuenta la repercusión negativa que pudiesen ocasionar a la ciudad y a sus habitantes. No les interesaba en absoluto el ordenamiento urbano de la ciudad, su configuración, su expansión urbana y su capacidad demográfica futura. Una correcta planificación urbana hubiese supuesto un gran desembolso para las compañías y ello no era conveniente para sus intereses. Por ello, durante el siglo XIX no fue posible coordinar los poderes políticos, económicos y sociales.

En cualquier caso, como indica R. Salas (2001), se produjeron avances importantes en la segunda mitad del siglo XIX. El llano barcelonés se urbanizó y los diversos pueblos del llano acabaron fusionándose con el área urbana de Barcelona. Durante esta época se produjo la finalización de la red básica ferroviaria de la ciudad y se procedió a completar el llamado ocho ferroviario. La red básica ferroviaria produjo una concentración industrial en los alrededores de las estaciones (Poble Nou y Clot) y en corredores como el Llobregat 
y el Besòs. El ferrocarril ayudó a la especialización industrial en ciudades como Martorell, Sabadell, Terrassa, Granollers o Mataró; consolidó los ejes radiales tradicionales y ayudó a la creación de asentamientos cerca de las fábricas. En esta época también se construyó la línea Barcelona-Sarriá. En el Ensanche, el ferrocarril de la calle Balmes dividía la Derecha y la Izquierda (Salas Buades, 2001) del mismo (la Derecha era el lugar donde se ubicaba la burguesía, las oficinas y los negocios, mientras que en la Izquierda se ubicaban los trabajadores y las actividades más modestas).

Más adelante, en 1872, el tranvía se implantó en Barcelona. En sus inicios era una red radial e interurbana y gestionada por una gran cantidad de compañías. No era aún un transporte colectivo masificado ya que el precio del billete era muy elevado para la clase trabajadora. Sin embargo, el tranvía motivó el desplazamiento y las relaciones de la ciudad en el área del Ensanche al norte de las Ramblas, aunque no supuso, en este período, un impacto decisivo en la construcción del Ensanche. Lo cierto es que la mala gestión de las administraciones a la hora de planificar el encaje de las redes ferro-viarias con el entramado urbano ha creado errores en la planificación urbana, especialmente en la segunda mitad del siglo XIX y su influencia se ha dejado notar en barrios como Sants, el Bon Pastor, la Vía Trajana o las ciudades de Sant Adrià del Besòs y Montcada i Rexach.

Sin embargo, en las dos primeras décadas del siglo XX se produjeron cambios notables en la configuración del ferro-carril y de la ciudad. Se crearon diversos proyectos para insertar las redes ferro-viarias en el conjunto urbano (algunos de los autores que más influencia tuvieron en este período fueron Eduardo Maristany, León Jaussely y Fernando Reyes). Durante esta época se efectuó la construcción ferro-viaria de segundo orden y los tranvías se extendieron. El Ensanche creció notablemente y se colmató el espacio entre Barcelona y los pueblos del Llano (la anexión municipal se produjo en 1897). Esta red era de vía estrecha, sus trazos eran más simples que los de la red básica y circulaba a menor velocidad. Solía ser de una sola vía y estar electrificada.

También se prolongó la línea de Sarrià hacia Sant Cugat, Sabadell y Terrassa y se construyó la línea Barcelona-Martorell, que transcurría por Sant Boi. En esta época, el ferrocarril influyó en la construcción de ensanches de pequeño tamaño y en la construcción de nuevas urbanizaciones. Un ejemplo de esto es la prolongación de la línea del ferrocarril de Sarrià (la Floresta, les Planes, Vallvidrera), que propició la proliferación de las segundas residencias. Por otra parte, en la línea Barcelona-Martorell se construyeron asentamientos urbanos cercanos a las fábricas instaladas con el propósito de acoger a los obreros que en ellas trabajaban. Al mismo tiempo, en el interior de Barcelona, los enlaces entre líneas provocaron un efecto barrera que impidió el crecimiento urbano, sobre todo en el este del Ensanche (Clot, Poble Nou).

De forma correlativa, el uso del tranvía se generalizó, los precios se estancaron y su velocidad aumentó. La estructura se mantuvo prácticamente igual (el centro y el noroeste de la ciudad continuaron siendo las zonas mejor servidas) y ayudó a consolidar el noroeste urbano (Sarrià-San Gervasi), aunque la red de tranvías se estructuró fundamentalmente en el centro de la ciudad (alrededor de la plaza de Cataluña).

Posteriormente, entre 1920 y 1936 se produjeron diversos avances significativos en la construcción de la red ferro-viaria. Las primeras redes de metro y de autobus se crearon en esta época. También aumentó el crecimiento urbano de Barcelona debido a la inmigración y se precisó de alojamientos asequibles. Por ello, se construyeron barracas en Montjuïc, Can 
Tunis u Hostafrancs y se crearon parcelaciones de autoconstrucción que propiciaron nuevas barriadas periféricas como las existentes en Borrás, Roquetes, Trinitat, Baró de Viver o el Monte Carmel. Sin embargo, es probable que la relación que tuvo el ferrocarril en la aparición del fenómeno del barraquismo sea más bien circunstancial y que se produjese debido a la marginalidad de las áreas afectadas.

Al mismo tiempo y poco a poco, la red ferro-viaria se permeabilizó y se soterró la línea de Balmes, aunque el resto de líneas tardó en desaparecer de la superficie. Estas líneas ferroviarias siguieron siendo una frontera para el crecimiento urbano y una delimitación de los espacios industriales.

Por otra parte, el tranvía se estancó en su crecimiento y, con la aparición del metro (1924) y el bus, este estancamiento se agravó. Sin embargo, el tranvía siguió influyendo en el desarrollo de la ciudad, sobre todo al noroeste (se consolidaron barriadas en Pedralbes, Vallvidrera y Penitents); aunque, no obstante consolidó áreas urbanas cuyos habitantes podían costear el trayecto. Por ello, en las barriadas del este de la ciudad, el tranvía dio un servicio insuficientemente al área. En esta época se crearon diversos planes como el Plan Macià y el Plan de Enlaces Ferroviarios de 1933. Estos planes pretendían integrar el ferrocarril y la urbe y proponían trazados alternativos, usualmente periféricos, en contraposición con la radialidad y centralidad de la red existente.

Más tarde, desde el inicio de la Guerra Civil hasta finales de los años cincuenta del siglo XX, se produjo un período previo a la municipalización de los transportes colectivos de Barcelona (en 1941 se creó R.E.N.F.E y se electrificaron varias líneas ferroviarias). En los años cincuenta del siglo XX, la ciudad inició un proceso de extensión urbana que aumentó el crecimiento del suelo ocupado en barriadas como Sant Andreu, Torre Baró, Vall d'Hebron y en municipios como Esplugues, Cornellà, Hospitalet, Santa Coloma o Sant Adrià. Las redes de transporte Barcelona se reconstruyeron durante este período, por lo que no hubo un avance significativo en las redes. En este período hubo una desconexión entre el crecimiento urbano y el crecimiento de las redes ferro-viarias. La urbe creció más rápidamente que estas redes, que además estaban estancadas y no proveían de comunicación a amplias áreas de las barriadas. El ferrocarril reforzó la estructura radial del área de influencia de Barcelona. Se crearon urbanizaciones de segunda residencia como Ciutat Florida y Santa María de Montcada que fueron construidas al tiempo que se implantaban las estaciones. También se crearon algunas urbanizaciones de primera residencia, como en Castelldefels, localidad asociada al ocio y al esparcimiento. Se construyeron primeras residencias en los pueblos del Llano y el Baix Llobregat, así como en las bolsas marginales de Barcelona y en determinadas ciudades de la comarca que poseían estación.

Posteriormente, entre finales de los años cincuenta hasta los inicios de los años setenta del siglo XX, la urbe se expandió de forma fuerte pero poco controlada. La política urbana optó por las grandes transformaciones mediante la construcción de polígonos (en Barcelona en Montbau, La Prosperitat, La Guineueta, San Martí, La Verneda... y también en la primera corona como en La Mina en San Adrià, el Pomar en Badalona, San Cosme en el Prat, Cinco Rosas en San Boi...). En 1957, por primera vez, fue mayor la población laboral de Barcelona que la residente. En ese año produjo la municipalización de los transportes colectivos de la ciudad y el ayuntamiento apostó por la ampliación del metro, promoviendo la eliminación del tranvía y el trolebús. Sin embargo, en este período, el metro no acabó de despegar y, en general, los transportes colectivos urbanos no desempeñaron un papel fundamental en el crecimiento urbano. 
A partir de 1965, el uso del vehículo privado empezó a masificarse y comenzó un nuevo hábito en las comunicaciones urbanas. Aumentó el transporte público por carretera y la red ferroviaria se racionalizó. Las líneas se gestionaron como conexiones regionales que daban servicio a áreas urbanas con gran índice de expansión. También se planificó una amplia red viaria para el vehículo privado. La ciudad se difundió a través de nuevos corredores y crecieron aceleradamente los núcleos más alejados al área metropolitana, en las salidas de las autopistas (Mataró). Se produjo una ruptura entre la dependencia del ferrocarril y los procesos de urbanización metropolitanos debida al uso generalizado del vehículo privado. Esta suburbanización implicó que el uso del vehículo privado se intensificase.

Desde principios de los años setenta hasta mediados de los ochenta del siglo XX, se produjeron cambios significativos en los transportes de Barcelona. Desaparecieron el tranvía y el trolebús de la ciudad, dejando como medios de transporte públicos al autobús, al metro $\mathrm{y}$ al ferrocarril. Hubo un cambio de tendencia respecto al crecimiento urbano. El espacio urbano creció de forma dispersa en torno a los ejes de las autopistas (A-7 por el corredor el Vallès, A-2 por el valle del Llobregat y la A-9 por el Maresme). Hubo un crecimiento tanto del suelo residencial como del industrial, que ampliaron la región metropolitana de Barcelona. Esto quedó reflejado en las encuestas de movilidad, que indicaban que la movilidad obligada experimentó una difusión hacia las coronas metropolitanas. Era un hecho que los viajes intermunicipales por motivo de trabajo se hacían cada vez más frecuentes y que era necesaria una mayor coordinación en los medios de transporte ferro-viarios y, por ello, con la creación de TMB (Transportes Municipales de Barcelona) se estructuraron las redes de autobús y metro para complementarlas. En este período, el metro duplicó su número de kilómetros, aunque mantuvo su estructura fundamental.

Es importante acotar que el metro, desde 1963, cuando se redactó el primer Plan de Urgencia, hasta 1985, tuvo cuatro proyectos de ampliación y reforma que, sin embargo, no fueron suficientes para abarcar toda el área metropolitana. Este hecho fue debido también a la mala gestión administrativa. La política de integración y modernización de la red llegó tarde respecto del crecimiento urbano, aunque finalmente el metro llegó a Hospitalet, Cornellà, Sant Adrià, Santa Coloma y Badalona, donde residía una buena parte de los trabajadores de Barcelona. La red ferroviaria se modernizó y RENFE reestructuró las estaciones centrales; las redes se reestructuraron (desapareció la estación del Norte); se mejoraron las frecuencias de paso y servicio y apenas se crearon líneas, excepto Barcelona Sants-Aeropuerto del Prat, la ronda exterior para mercancías y algunos ramales.

Desde mediados de los ochenta hasta finales de la década de los noventa del siglo XX, se produjeron cambios sustanciales. Las pautas de localización territorial implicaron una mayor difusión y consumo de suelo (este tipo de urbanización es muy dependiente del vehículo privado ya que es muy difícil que el transporte colectivo de pasajeros pueda llegar a áreas tan dispersas). La movilidad extramunicipal estaba en aumento y cada vez había más personas que transitaban en vehículo privado , distribuyendo así los viajes de forma cada vez más dispersa. Al mismo tiempo el autobús se supeditó al metro, el cual se amplió y mejoró la calidad de sus estaciones coincidiendo con una integración tarifaria parcial. Fue en este período cuando el metro se consolidó como el transporte público más usado en Barcelona y en su área metropolitana. 
Por su parte, RENFE modernizó el ferrocarril de cercanías y la red ferroviaria se intensificó aumentando las frecuencias de paso y llegando al límite máximo de capacidad de viajeros. El ferrocarril experimentó un aumento de usuarios debido al encarecimiento de los carburantes, a la insuficiencia de la red viaria y a la modernización de los ferrocarriles. No obstante, pese a estos buenos resultados, no se maximizaron determinadas oportunidades, como la cita olímpica de 1992, para poder realizar obras de gran calado en la ciudad. Se eliminaron las líneas de la costa y sus estaciones, y se reorganizaron las líneas ferroviarias de cercanías. Sin embargo, no se construyó una obra tan necesaria como la de un túnel ferroviario paralelo a la Ronda del Litoral, situado entre las desembocaduras de los ríos Besòs y Llobregat, que habría resuelto muchos de los problemas de movilidad en Barcelona.

A pesar de ello, la red viaria también creció (A-7 y rondas), reduciendo así el tiempo de viaje en el área metropolitana y entre áreas periféricas. Se consiguió que la mayoría de los núcleos urbanos del área metropolitana fuesen accesibles en 40-50 minutos en transporte colectivo. Fuera de estos recorridos, el tiempo de viaje aumentó muy considerablemente, mientras que en vehículo privado se pudo llegar a la mayoría de las poblaciones de la segunda corona en menos de media hora.

Más tarde, como indica M. Taravilla Rodríguez (2010), ocurrieron una serie de hechos significativos: en 1992 la estación de Francia se remodeló y en 1993 entró en funcionamiento el metro regional, una denominación para los trenes de cercanías que modificaban sus servicios y frecuencias. En 1995 se inauguró el tramo entre Cerdanyola del Vallès y la Universitat Autònoma y en 1997 se inauguró el Euromed, que era un servicio de alta velocidad entre Barcelona y Alicante, pasando por Valencia. En 2005, una ley permitió la separación de las infraestructuras y de los servicios ferroviarios, y se crearon las empresas adscritas al Ministerio de Fomento: ADIF y RENFE-Operadora. La primera se encarga desde entonces de administrar y construir infraestructuras ferroviarias de la construcción de RFIG (Red Ferroviaria de Interés General), así como de las nuevas líneas. La segunda, por su parte, presta servicios públicos ferroviarios de viajeros (el Estado la compensa económicamente) y de mercancías, y realiza mantenimientos de material móvil.

Más tarde, durante la primera década del siglo XXI, se implantaron en Barcelona el metro ligero y la alta velocidad. La implantación del Trambesòs y el Trambaix ha demostrado el grado de aceptación popular del medio. La unión de ambas redes por la Diagonal tendría un impacto positivo sobre el paisaje urbano, el medio socioeconómico y el conjunto de la sociedad. Esta implantación por la Diagonal repercutirá en la circulación por la trama ortogonal y agilizará la sustitución progresiva del vehículo privado (Taravilla Rodríguez, 2010). Por otra parte, la alta velocidad entre Madrid y Barcelona llegó a Lleida en 2003, a Tarragona en 2006, a Barcelona en 2008 y a la frontera francesa en 2013. Los diferentes itinerarios propuestos para el paso del TAV en Barcelona (al aeropuerto, cruzar por el Vallès, estación intermodal entre Paseo de Gracia y Balmes, cruzar por el litoral de Barcelona...) han supuesto retrasar la implantación de la alta velocidad. Concretamente, el TAV en Barcelona llegó en tres fases; una entre el Prat de Llobregat y Sants, otra entre Sants y Sagrera y otra entre Sagrera y la reordenación urbana del sector Sagrera-Sant Andreu.

En el período señalado, se han realizado diversos planes de actuación. El Plan estratégico de infraestructuras y transporte 2005-2020 propuso coordinar las administraciones competentes y adaptar las infraestructuras a la accesibilidad real del territorio. Para ello deben 
mejorarse los servicios públicos efectivos de acceso hasta los nodos de las redes de altas prestaciones. También se realizó el Pla de transports de viatgers de Catalunya 2008-2012. Estos planes indican que hay aspectos importantes que hay que mejorar en la articulación del transporte colectivo de la ciudad. Estos aspectos son: la mejora global de los accesos a la red de transporte público para personas con problemas de movilidad o deficiencia sensorial; la necesaria desaparición de los intersticios espaciales de la ciudad generados por los trazados ferroviarios; la conclusión de la línea 9 de metro y, por último, la necesidad de normalizar el transporte de mercancías por ferrocarril. A este respecto hay que indicar que en 2008 entró en funcionamiento el ramal de mercancías construido entre Can Tunis y Castellbisbal. Este trazado conecta las instalaciones portuarias y las terminales de mercancías del Morrot y Can Tunis, en el puerto de Barcelona, con el corredor ferroviario del Vallès (Castellbisbal-Mollet) y la línea de Vilafranca. Se pretendía eliminar la saturación de las líneas 2 y 4 y mejorar sus frecuencias. También se buscaba mejorar las comunicaciones con Castellbisbal y las conexiones y la explotación a los operadores de mercancías así como reducir la contaminación. Estas actuaciones son importantes, ya que el transporte de mercancías ferroviario ha pasado de 13,73 millones de toneladas en 2004 a 8,95 millones de toneladas en 2007 y ello es realmente preocupante aunque se están tomando medidas para poder corregir esta situación.

Un ejemplo paradigmático de la importancia creciente del ferro-carril en las comunicaciones, en la planificación y en la economía se produjo en 2009, cuando se implantó un nuevo servicio de transporte ferroviario de contenedores denominado "Barcelyon Express" entre el puerto de Barcelona y la ciudad francesa de Lyon, que une las terminales de contenedores del puerto barcelonés (TBC, TerCat) con la Terminal de Vénissieux (Naviland Cargo) situada en Lyon. Este servicio puede transportar contenedores marítimos y cisternas. Resulta un servicio de transporte altamente competitivo que puede captar el transporte ferrroviario de mercancías de amplias zonas de España y Francia.

Teniendo en cuanta el análisis precedente, no cabe duda de la importancia e interrelación existente entre la planificación urbana y la planificación ferro-viaria. Los actuales planes de actuación territorial deben tener en cuenta siempre esta estrecha sinergia.

\section{ANÁLISIS DE LOS DATOS EMPÍRICOS}

\section{IV.1. Distribución de los equipamientos de Barcelona}

En este primer análisis se tiene en cuenta la distribución de los equipamientos de Barcelona y su relación con las infraestructuras de transporte. Para ello, primeramente es necesario observar cuál es la distribución de los equipamientos en Barcelona en el período 2007-2009.

La densidad de equipamientos de Barcelona actual y prevista se distribuye de acuerdo a como se presentan en las figuras 1 y 2 . Los equipamientos educativos y los centros oficiales constituyen la mitad del total; los equipamientos culturales y de ocio, los sanitarios y los deportivos suman un $30 \%$ más; el $20 \%$ restante se distribuye entre los cementerios y servicios funerarios, los tratamientos de residuos y depuradoras, los mercados y centros comerciales, las oficinas de correos, los equipamientos de seguridad y los equipamientos de transporte. Las estaciones de ITV y otro tipo de equipamientos representan un porcentaje muy marginal. 
Figura 1

DENSIDAD DE EQUIPAMIENTOS DE BARCELONA, 2007

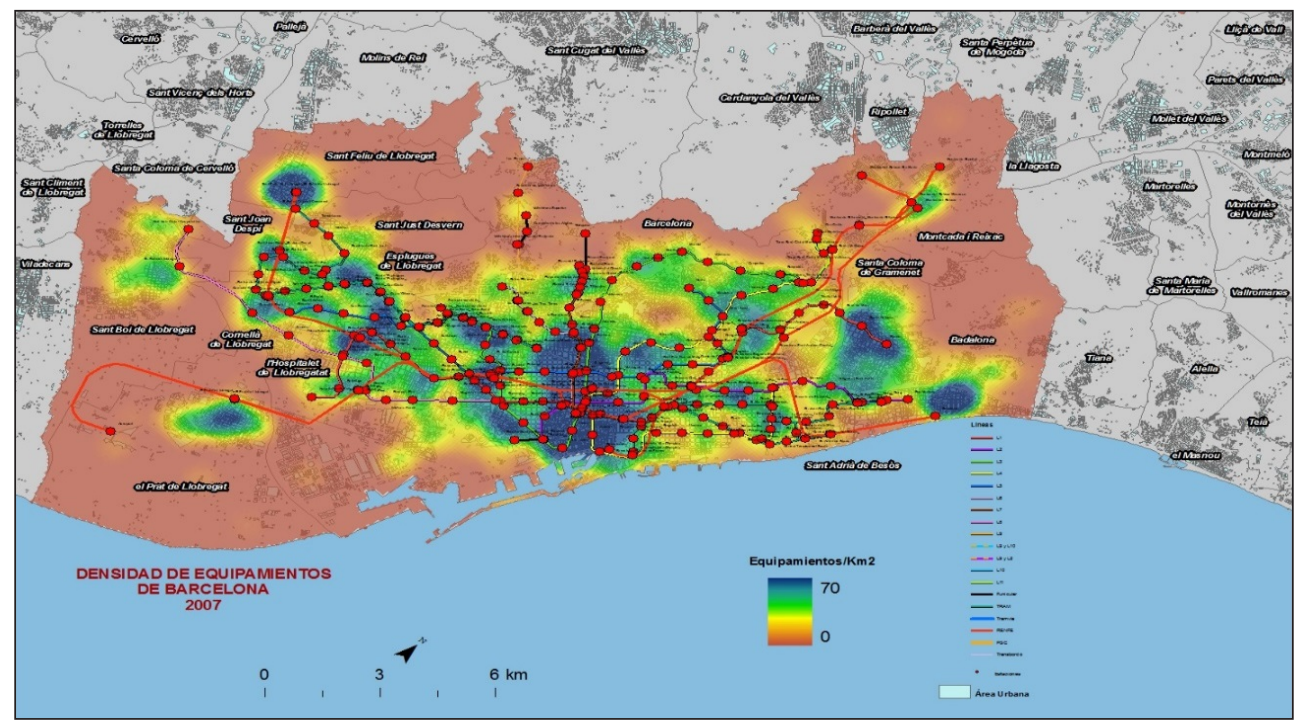

Fuente: elaboración propia a partir de datos de A.M.B.

Figura 2

DENSIDAD PREVISTA DE EQUIPAMIENTOS DE BARCELONA PREVISTA EN EL AÑO MÁS ALLÁ DE 2020

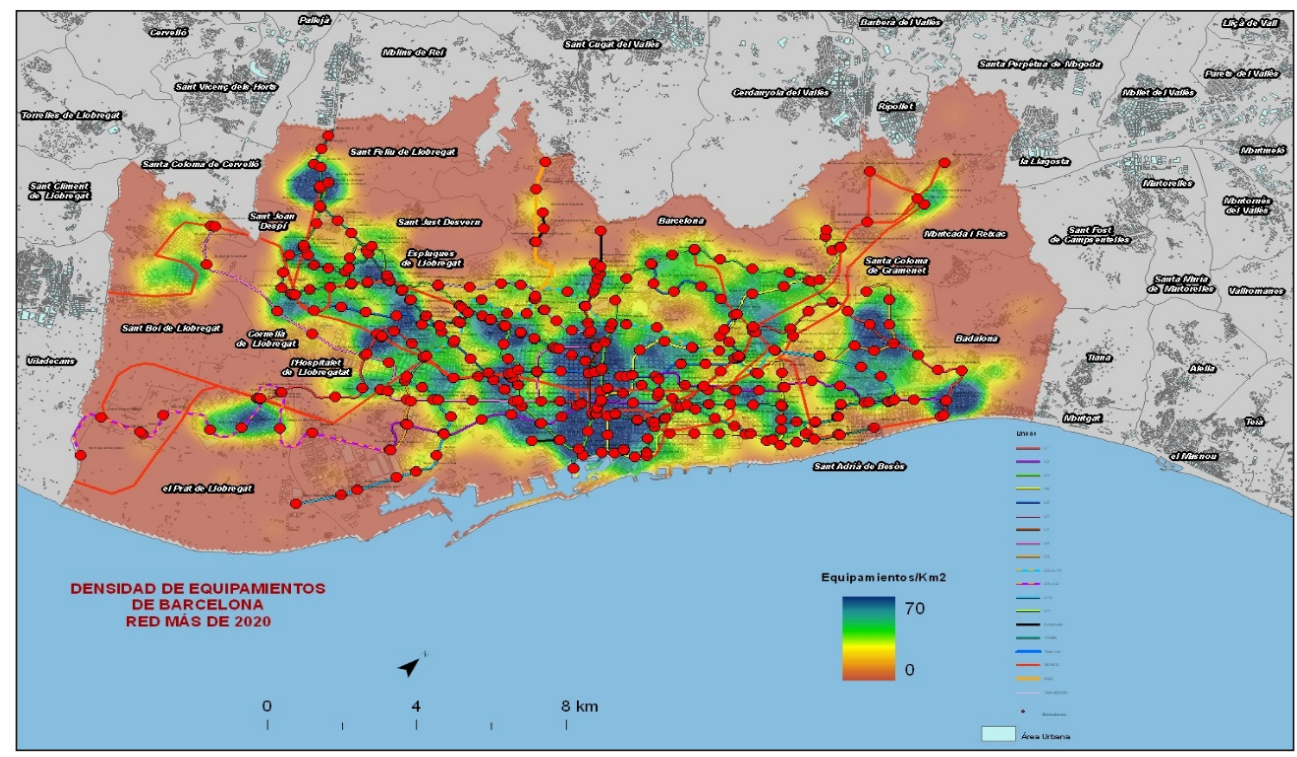

Fuente: elaboración propia a partir de datos de A.M.B. 
Se pueden dividir los equipamientos en función de su densidad, ya sea baja, media o alta. Dentro del grupo de los equipamientos de densidad y cantidad baja se hallan los cementerios y servicios funerarios, los mercados y centros comerciales, los depósitos de vehículos, las oficinas de correos, los equipamientos de seguridad y los equipamientos de tratamientos de residuos y depuradoras. Dentro del grupo de equipamientos de densidad y cantidad media se hallan las instalaciones deportivas, los equipamientos de transporte, los equipamientos sanitarios, los centros oficiales y los equipamientos de cultura y ocio.

Hay que realizar una mención especial a los equipamientos de transporte debido a su relevancia en este análisis. Es importante resaltar que los equipamientos de transporte de Barcelona tienen una distribución desigual. Principalmente se hallan presentes en el municipio central, aunque existen importantes excepciones. Dentro del municipio suelen hallarse distribuidos de forma más o menos homogénea por todo el Ensanche. Son cuatro las agrupaciones de equipamientos de transporte más importantes y se hallan en torno a la estación de Sants, a la estación de Catalunya, en la Zona Franca y en Badalona. La red ferro-viaria del año 2007 proporciona una buena cobertura de acceso a estos equipamientos, básicamente por el hecho de encontrarse mayoritariamente dentro del municipio barcelonés (figura 1). Sin embargo, los importantes equipamientos presentes en la Zona Franca y en Badalona no disponían de una buena conexión ferro-viaria. En el año más allá de 2020 (figura 2), se estima que la ampliación de la red ferro-viaria solventará esta cuestión al proporcionar acceso global a todos los equipamientos.

Otros equipamientos, como los sanitarios, poseen una distribución poco homogénea. Los equipamientos sanitarios de atención primaria se hallan uniformemente distribuidos pero no así los hospitales, que se aglomeran muy claramente en las áreas central y norte de la ciudad de Barcelona. Debido a la importancia de estos equipamientos, las instalaciones ferro-viarias han tendido a acercarse a ellos y por lo tanto, estas instalaciones sanitarias disponen de una muy buena conectividad, excepto en las áreas urbanas más periféricas como Badalona. En el año más allá de 2020, la red ferro-viaria prevista dará una conectividad total a estos equipamientos sanitarios.

Por otra parte, dentro del grupo de equipamientos que poseen una cantidad y densidad elevada, se encuentran los equipamientos educativos. Estos poseen una distribución muy homogénea en toda el área metropolitana, aunque hay importantes intersticios sin servicio en el municipio central, especialmente en determinadas áreas relativamente céntricas del Ensanche. En los municipios más periféricos del área metropolitana de Barcelona los equipamientos educativos tienden a aglomerarse en el centro urbano, aunque su distribución es verdaderamente amplia. La excepción la pueden constituir los centros de educación superior, las universidades. Éstas se hallan presentes en torno a la Diagonal, a Ciutat Vella y al norte del municipio de Barcelona. La red ferro-viaria de 2007 proporciona cobertura a buena parte de este tipo de equipamientos, pero en las áreas urbanas más periféricas existe un amplio desabastecimiento de conexión. Se prevé que en el año más allá de 2020 esta situación se habrá corregido totalmente.

Para concluir el análisis de la distribución de los equipamientos, hay que tener en cuenta otros factores (figuras 3 y 4), como la densidad de población por entramado urbano (siendo predominante el intervalo de 25.000-50.000 habitantes por $\mathrm{km}^{2}$ ) o por tipo de edificación (siendo predominante el intervalo de 30.000-35.000 habitantes por $\mathrm{km}^{2}$ ). Se puede observar 
Figura 3

DENSIDAD DE EQUIPAMIENTOS POR ÁREA DE LAS ESTACIONES DEL SISTEMA FERRO-VIARIO INTEGRADO DE BARCELONA, 2009

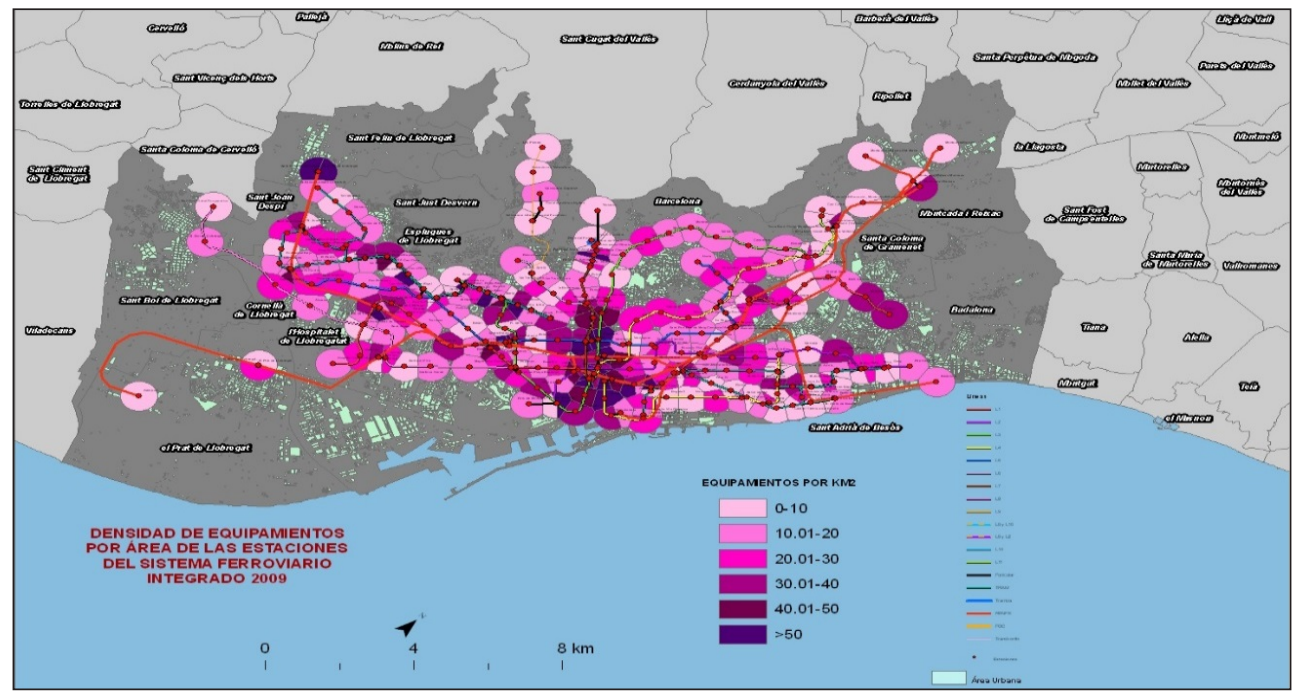

Fuente: elaboración propia a partir de datos de A.M.B.

Figura 4

DENSIDAD DE EQUIPAMIENTOS POR ÁREA DE LAS ESTACIONES DEL SISTEMA FERRO-VIARIO INTEGRADO DE BARCELONA, PREVISTA EN EL AÑO MÁS ALLÁ DE 2020

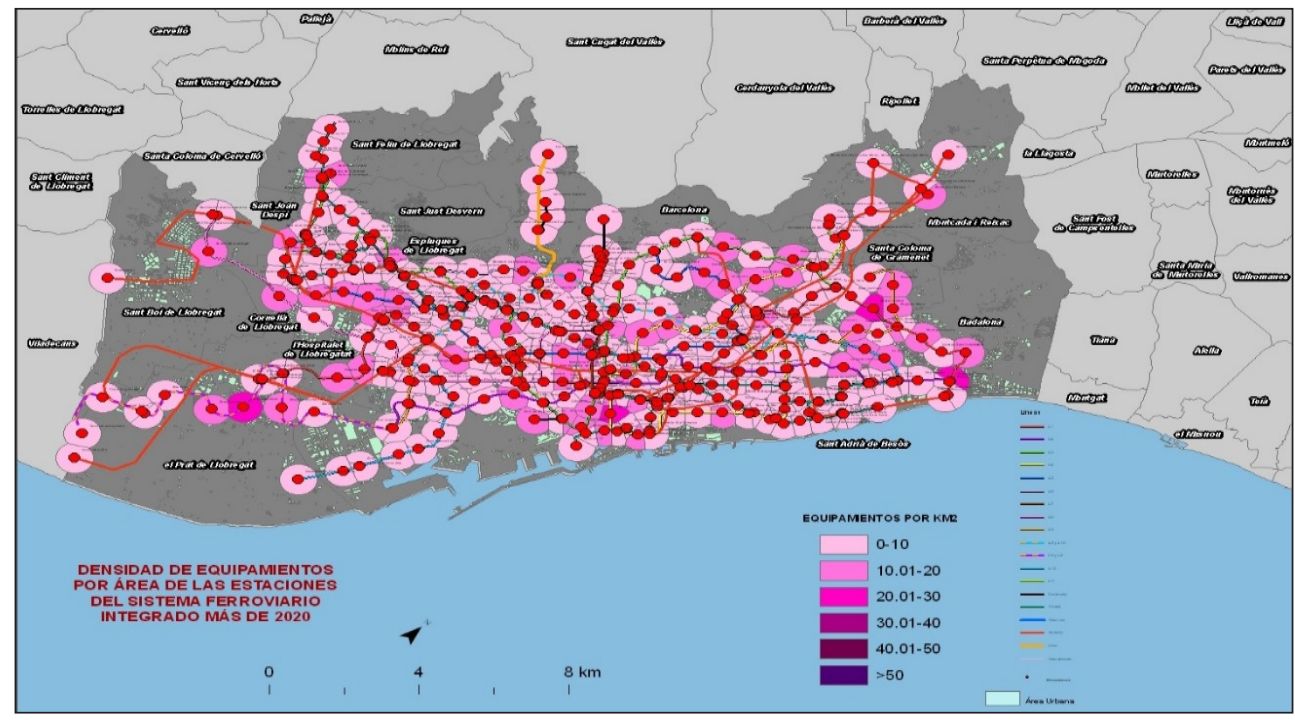

Fuente: elaboración propia a partir de datos de A.M.B. 
cómo los equipamientos se hallan presentes abrumadoramente en las áreas de densidad de población correspondientes a los intervalos 0-20.000 y 20.000,01-40000 habitantes por km². Esta es una cifra de densidad relativamente baja, por lo que se puede afirmar que los equipamientos dan servicio a la población en áreas uniformemente pobladas y con densidades de población razonables. Esto significa que la saturación de dichos equipamientos también es moderada. También se observa que la mayoría de los equipamientos se sitúan en edificaciones urbanas, siendo infrecuente la implantación de equipamientos en zonas de edificación aislada o residencial.

$\mathrm{Al}$ analizar la densidad de los equipamientos en función del área de cobertura estimada de cada estación de la red ferro-viaria, se comprueba cómo en 2009 las estaciones más céntricas aglutinaban una gran cantidad de equipamientos desde la estación Diagonal hasta el puerto (de 40 a más de 50 equipamientos por $\mathrm{km}^{2}$ ). Le sigue un área de densidad intermedia (10-20 equipamientos por $\mathrm{km}^{2}$ ) y, posteriormente, una serie de áreas de alta densidad (30-40 equipamientos por $\mathrm{km}^{2}$ ) en los extremos de las líneas correspondientes con las áreas urbanas centrales de los municipios periféricos del área metropolitana de Barcelona. Esta estructura se modificará sustancialmente en el año más allá de 2020, ya que la red ferro-viaria se habrá ampliado para entonces enormemente y convertid en una red densa y compleja. De esta manera, al haber más estaciones ferro-viarias en el mismo espacio, se distribuirán de forma más homogénea los equipamientos. Los intervalos de 0-10 y 10-20 equipamientos por $\mathrm{km}^{2}$ serán los predominantes.

Se puede concluir que la totalidad de equipamientos de Barcelona presenta un aspecto muy característico. Existe una gran aglomeración de equipamientos en el área central, en Ciutat Vella y en el centro del Ensanche, alrededor de la cual hay diversas aureolas de equipamientos de diversa densidad. En las áreas urbanas de los municipios más periféricos del área metropolitana de Barcelona, los equipamientos tienden a aglomerarse en el centro, formando una serie de constelaciones y nebulosas que salpican el continuo urbano. Las redes ferro-viarias poseen la misma estrategia espacial. Suelen conectar las áreas urbanas más céntricas y por ello suelen implantarse en los centros de las urbes. Es por tanto, una cuestión de localización espacial ambiental común. La red ferro-viaria prevista más allá de 2020 aumentará la conexión general con estos equipamientos.

La red ferro-viaria y la distribución de los equipamientos poseen una indudable relación. Los equipamientos tienden a aglomerarse en la ciudad de Barcelona, especialmente en su área central, y también en las áreas urbanas centrales de los municipios más periféricos de su área metropolitana. Las redes ferro-viarias reproducen el mismo fenómeno. La población tiene un mayor acceso a las áreas más céntricas y por ello los centros urbanos suelen estar muy bien conectados con las redes ferro-viarias. Como ya se ha dicho, es una cuestión de localización espacial ambiental común, lo cual corrobora la teoría de que las infraestructuras ferro-viarias y el crecimiento y desarrollo urbano están imbricados. En la ampliación de las redes ferro-viarias previstas en el año más allá del 2020, se tiene en cuenta de forma muy notoria la localización de los equipamientos, especialmente aquellos que se hallan en la periferia del área metropolitana. En este caso, son las infraestructuras de transporte las que han planificado su estructura en función de los equipamientos, aunque también se puede dar el hecho contrario, que un equipamiento decida localizarse cerca de una infraestructura de transporte ya implantada. 


\section{IV.2. Los centroides de la red ferro-viaria y del área urbana de Barcelona}

Los centroides (punto central de un área) de la red ferro-viaria y del área urbana de Barcelona proporcionan datos de gran relevancia para entender cuáles han sido las pautas ,de desarrollo de ambas (tabla 1 y figuras 5, 6, 7, y 8). En el siguiente análisis se tienen en cuenta tanto la distancia entre los centroides urbanos (punto central del área urbana) y ferro-viario (punto central del área conformada por la suma de los ámbitos de las estaciones ferro-viarias en un radio de 500 metros alrededor de cada estación) como las áreas urbana y aquella conformada por la suma de los ámbitos de las estaciones ferro-viarias. Ambos datos (distancia entre centroides y áreas) proporcionan la información necesaria para saber si un área urbana afecta al desarrollo de una red ferro-viaria a la inversa o mutuamente. El análisis compara el área urbana de Barcelona y su área metropolitana con la red de metro de 1926 y la prevista más allá de 2020 y con el sistema ferro-viario integrado (metro, metro ligero, ferrocarril, tranvía, funicular) entre 2009 y el previsto más allá de 2020.

Tabla 1

CENTROIDES EN BARCELONA

\begin{tabular}{|l|c|c|c|}
\hline \multicolumn{1}{|c|}{ Fecha } & Área Urbana $\left.\mathbf{( k m}^{2}\right)$ & $\begin{array}{c}\text { Área Ámbito } \\
\text { Estaciones }\left(\mathbf{k m}^{2}\right)\end{array}$ & $\begin{array}{c}\text { Distancia entre } \\
\text { centroides }(\mathbf{m})\end{array}$ \\
\hline Metro 1926 & 30,27 & 8,43 & 1.243 \\
\hline Metro 1950 & 49,26 & 10,11 & 2.080 \\
\hline Metro 1966 & 49,26 & 43,46 & 776 \\
\hline Metro 1980 & 86,56 & 34,32 & 1.192 \\
\hline Metro 2000 & 143,7 & 63,01 & 1.363 \\
\hline Metro 2009 & 148,47 & 67,33 & 864 \\
\hline Metro 2020 & 148,47 & 92,6 & 1.213 \\
\hline Metro >2020 & 154,93 & 101,42 & 604 \\
\hline SFI 2009 & 154,96 & 92,43 & 868 \\
\hline SFI 2020 & 156,35 & 114,12 & 1.147 \\
\hline SFI >2020 & 164,59 & 126,85 & .116 \\
\hline
\end{tabular}

Fuente: elaboración propia a partir de datos de AMB y ATM. *SFI: Sistema Ferro-viario Integrado.

En 1926, Barcelona abarcaba poco más de $30 \mathrm{~km}^{2}$ de área urbana, mientras que el área que ocupaban las estaciones de metro (teniendo en cuenta un área por estación que abarque 500 metros alrededor de cada una de ellas) era de $8,43 \mathrm{~km}^{2}$. La distancia entre el centroide del área urbana y del área conjunta del total de las estaciones de la red era de 1.243 metros. En este punto la relación entre área urbana y red ferro-viaria era incipiente pero existía una clara relación entre ambas. 
Figura 5

CENTROIDES DEL METRO DE BARCELONA, 1926

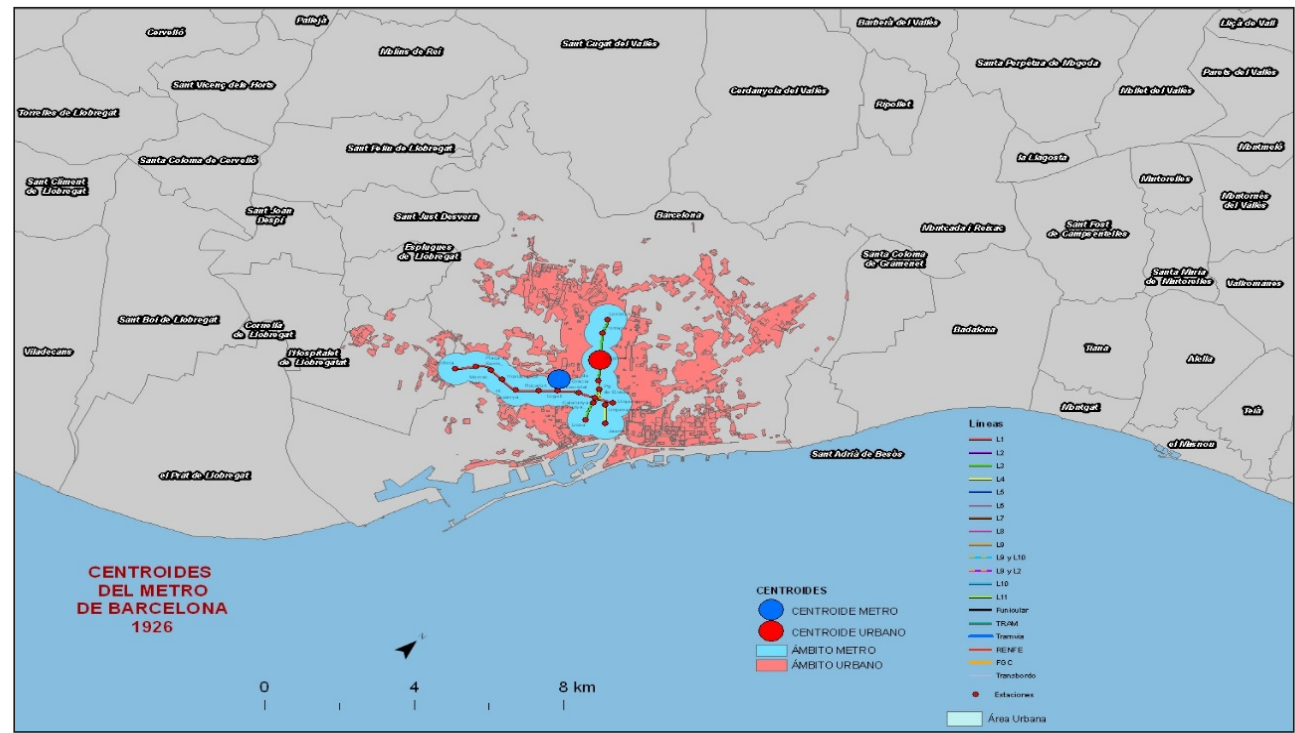

Fuente: elaboración propia a partir de datos de A.M.B., T.M.B., A.T.M, F.G.C y R.E.N.F.E.

Figura 6

CENTROIDES DEL METRO DE BARCELONA, 1980

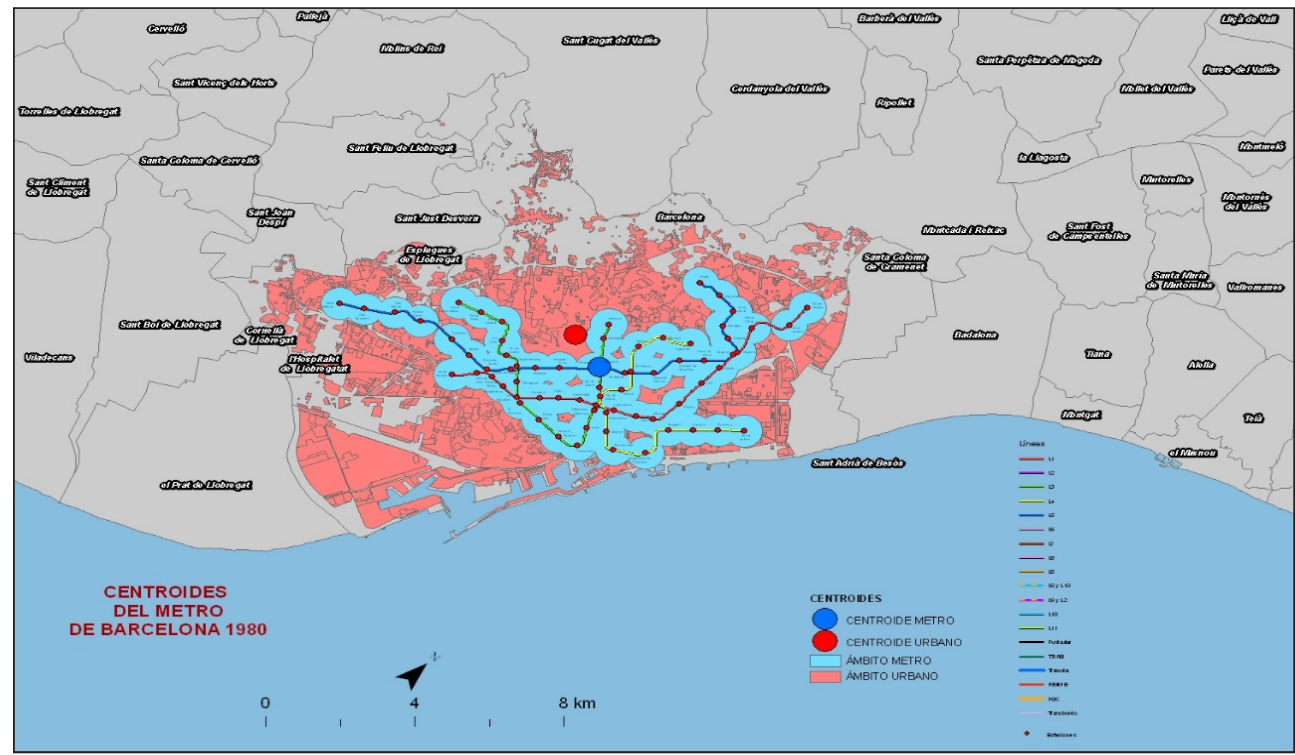

Fuente: elaboración propia a partir de datos de A.M.B., T.M.B., A.T.M, F.G.C y R.E.N.F.E. 
Figura 7

CENTROIDES DEL METRO DE BARCELONA, 2009

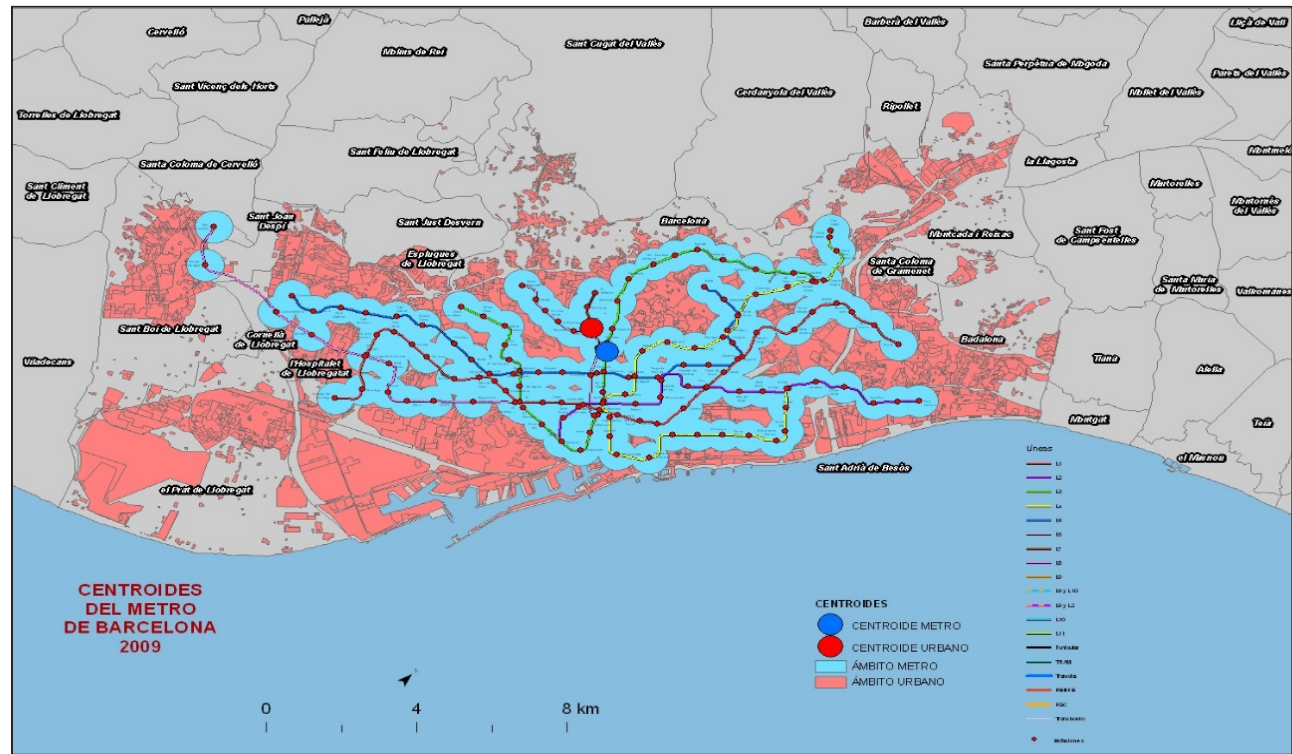

Fuente: elaboración propia a partir de datos de A.M.B., T.M.B., A.T.M, F.G.C y R.E.N.F.E.

Figura 8

CENTROIDES DEL METRO DE BARCELONA PREVISTA EN EL AÑO MÁS ALLÁ DE 2020

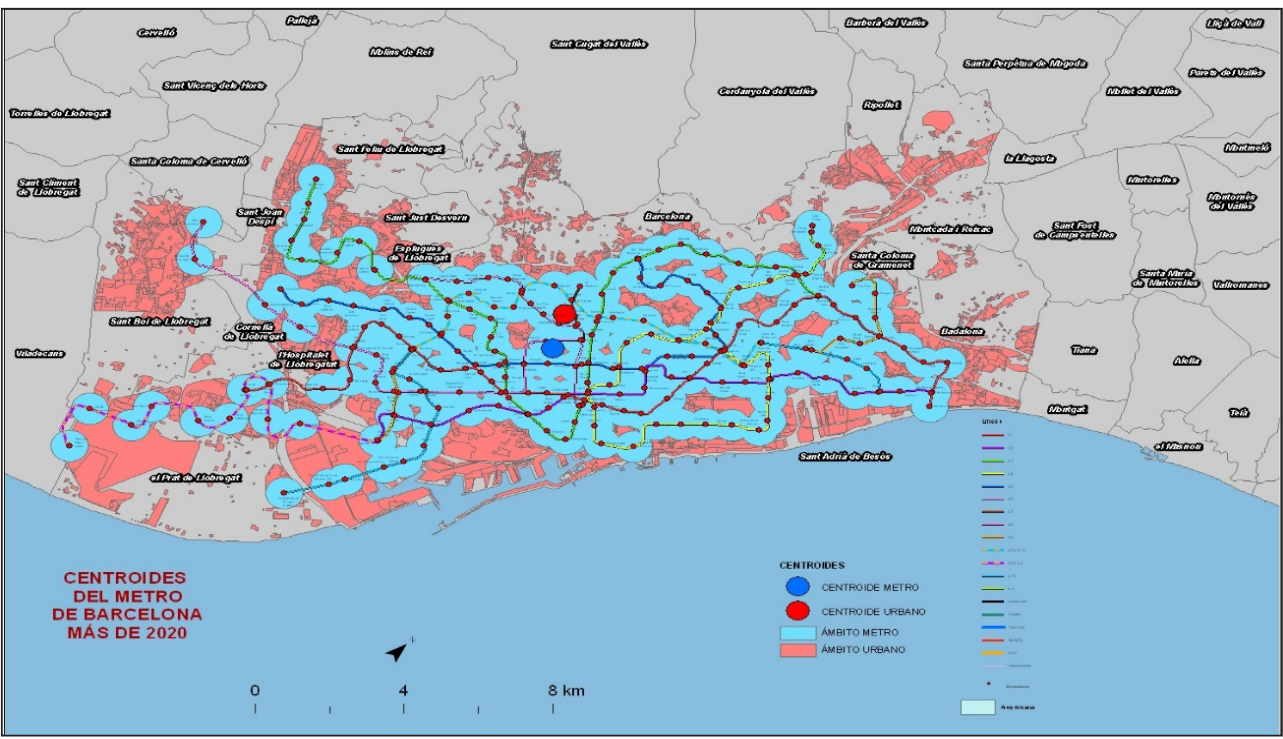

Fuente: elaboración propia a partir de datos de A.M.B., T.M.B., A.T.M, F.G.C y R.E.N.F.E. 
La Guerra Civil y la posguerra paralizaron la ampliación de la red de metro y, así, en 1950 se produjo una gran disparidad entre el área urbanizada y el área que abarcaban las estaciones. El área urbana suponía casi $50 \mathrm{~km}^{2}$, mientras el área que abarcaban las estaciones era de sólo $10 \mathrm{~km}^{2}$. La distancia entre centroides superó los 2.000 metros.

En 1980, la desproporción entre el área urbana consolidada y el área de la red de metro seguía siendo muy pronunciada. Había más de $85 \mathrm{~km}^{2}$ de área urbana frente a $35 \mathrm{~km}^{2}$ del área que abarcaba la red de metro con una separación entre centroides de casi 1.200 metros.

Es en 2000 cuando el crecimiento del área urbana alcanzó su estabilidad con $150 \mathrm{~km}^{2}$ urbanizados. Se produjo entonces una colmatación del territorio. Esta cifra se mantuvo casi constante en años posteriores, pero no así el área que ocupaban las estaciones de metro. En 2000, el área de las estaciones de metro ocupaba $67 \mathrm{~km}^{2}$ y los centroides estaban a $1.363 \mathrm{~m}$ de distancia. En 2009, la superficie relativa a las estaciones se mantuvo casi invariable con $67 \mathrm{~km}^{2}$, pero la distancia entre centroides se redujo a $864 \mathrm{~m}$.

Sin embargo, la red prevista para 2020 llegará a más de $90 \mathrm{~km}^{2}$ del área que abarcan las estaciones, con más de 1.200 metros de separación entre los centroides, mientras que la red prevista para 2020 poseerá una distancia entre centroides de $1.116 \mathrm{~m}$ y las estaciones abarcarán un área de $101,42 \mathrm{~m}^{2}$.

$\mathrm{Si}$ el análisis se realiza teniendo en cuenta el sistema ferro-viario integrado, los resultados que se obtienen son que en 2009 la superficie de las estaciones representaba las dos terceras partes de la superficie urbana y sólo existía una distancia entre centroides de 604 metros: el mínimo que se ha podido analizar.

En 2020, el área urbana será de $156 \mathrm{~km}^{2}$, mientras el área de cobertura de las estaciones del sistema ferro-viario integrado será de $114 \mathrm{~km}^{2}$ y la distancia entre centroides medirá 868 metros. En 2020, el área urbana será de 164 km², el área de cobertura de las estaciones será de $126 \mathrm{~km}^{2}$ y la distancia entre centroides medirá apenas 1.147 metros.

Por lo tanto, se puede deducir que ha habido un paulatino acercamiento y correlación entre la red ferro-viaria de la ciudad central de Barcelona y de su área metropolitana y, además, que, previsiblemente, se prolongará hasta 2020. Si bien la red de metro ha ido siempre a la zaga respecto de Barcelona, ha procurado seguir sus pautas de crecimiento, con la excepción, muy notoria, del amplio período correspondiente a la Guerra Civil y posguerra, que cercenaron el crecimiento de la red. Los actuales planes de ampliación tienen en cuenta la estructura urbana existente, cuya expansión se estabilizó en torno a los 150 $\mathrm{km}^{2}$ debido a los condicionantes topográficos y naturales. Sin embargo, la red ferro-viaria en su conjunto continúa su ampliación sin detenerse y pretende abarcar la totalidad del continuo urbano. La distancia entre los centroides se suele mantener de forma casi constante entre los 700 y los 1.200 metros de distancia de media. Ello significa que el avance del área urbana y de las estaciones suelen ir parejos, aunque la evolución de la red ferroviaria y de la expansión urbana ha sido compleja.

\section{IV.3. Evolución del precio de la vivienda y estructura ferro-viaria de Barcelona}

La evolución del precio del suelo en Barcelona ha sido significativa, como indica J. Roca i Cladera (1986). La base de datos existente ha permitido analizar el precio del suelo en el 
municipio de Barcelona en los años 1951, 1960, 1972 y 1978 (figuras 9, 10 y 11). Los aspectos más destacables en esta serie cronológica son: la evolución del precio de la vivienda y la evolución en la distribución de los precios de la vivienda.

Figura 9

PRECIO DEL SUELO DE BARCELONA, 1951

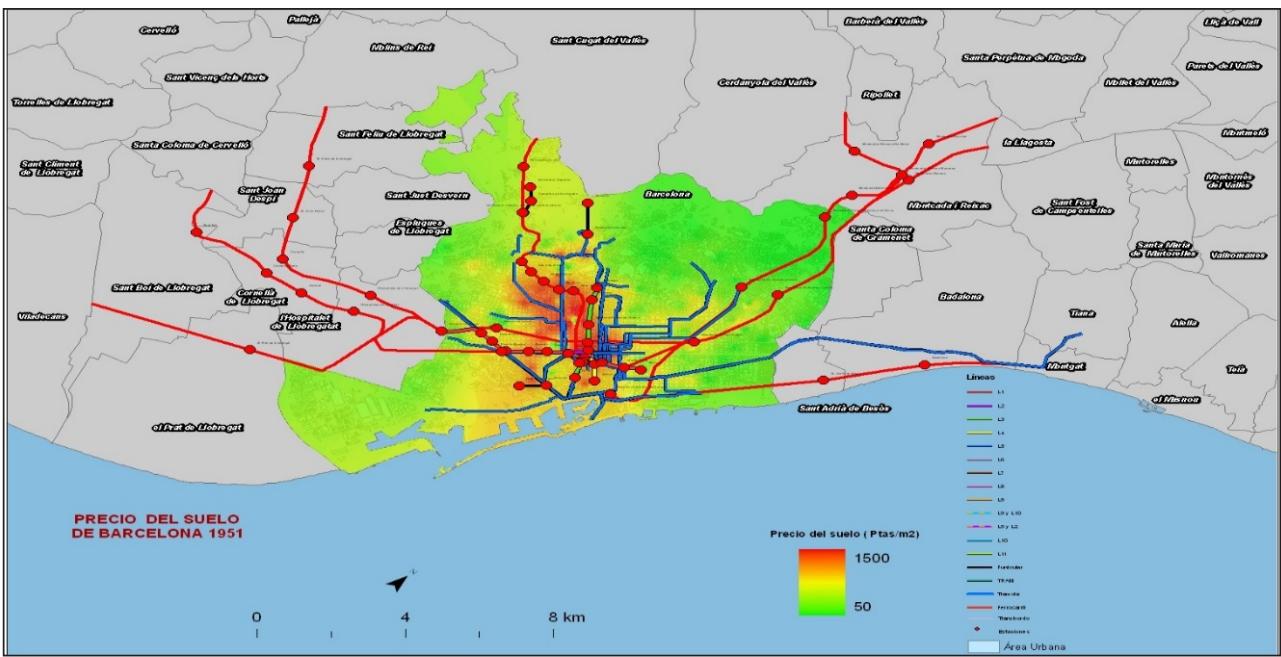

Fuente: elaboración propia a partir de Maragall. P. (1979).

Figura 10

PRECIO DEL SUELO DE BARCELONA, 1972

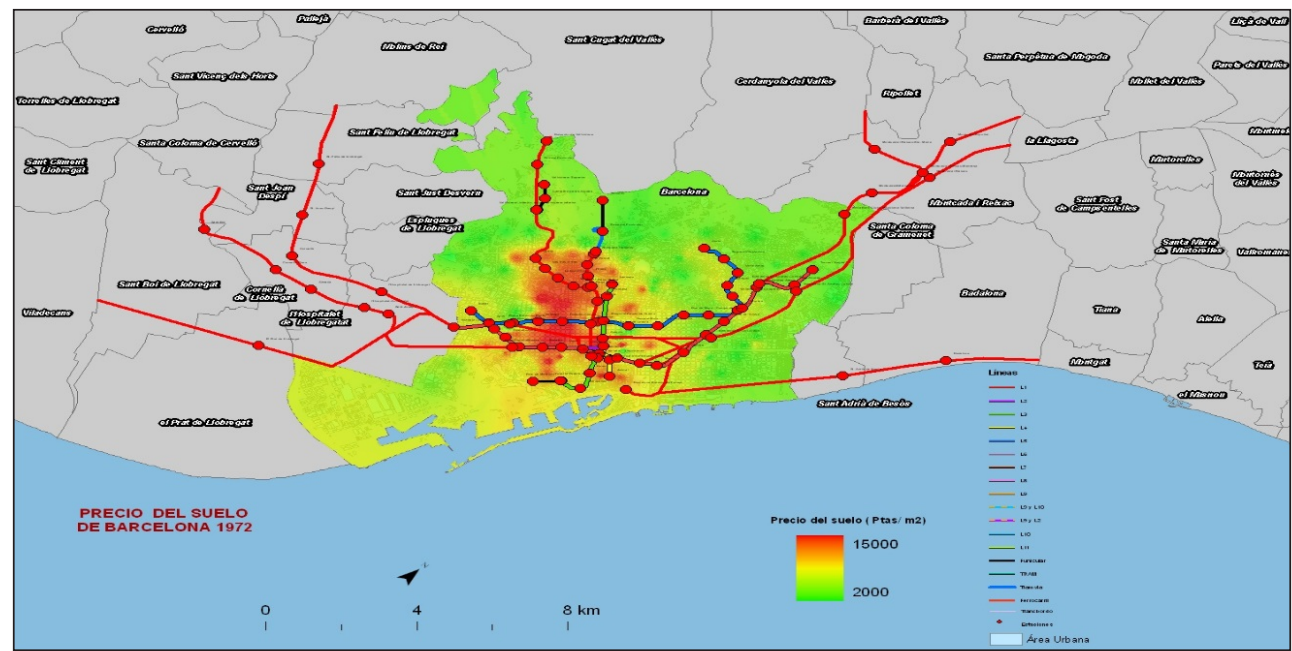

Fuente: elaboración propia a partir de Maragall. P. (1979). 
Entre 1951 y 1978, el precio de la vivienda creció considerablemente a causa de la inflación. De un precio máximo de 1.500 pesetas por $\mathrm{m}^{2}$ en 1951 se pasó a 50.000 pesetas por $\mathrm{m}^{2}$ en 1978, siendo el salto cuantitativo total más notorio entre 1972 y 1978 (15.000 pesetas por $\mathrm{m}^{2}$ frente a 50.000 pesetas por $\mathrm{m}^{2}$ ). Sin embargo, a nivel porcentual, el salto cuantitativo más prominente fue el producido entre 1960 y 1972, ya que se pasó de 2.000 pesetas por $\mathrm{m}^{2}$ a 15.000 pesetas por $\mathrm{m}^{2}$, es decir, se multiplicó por 7 el precio máximo de la vivienda.

Figura 11

PRECIO DEL SUELO DE BARCELONA, 1978

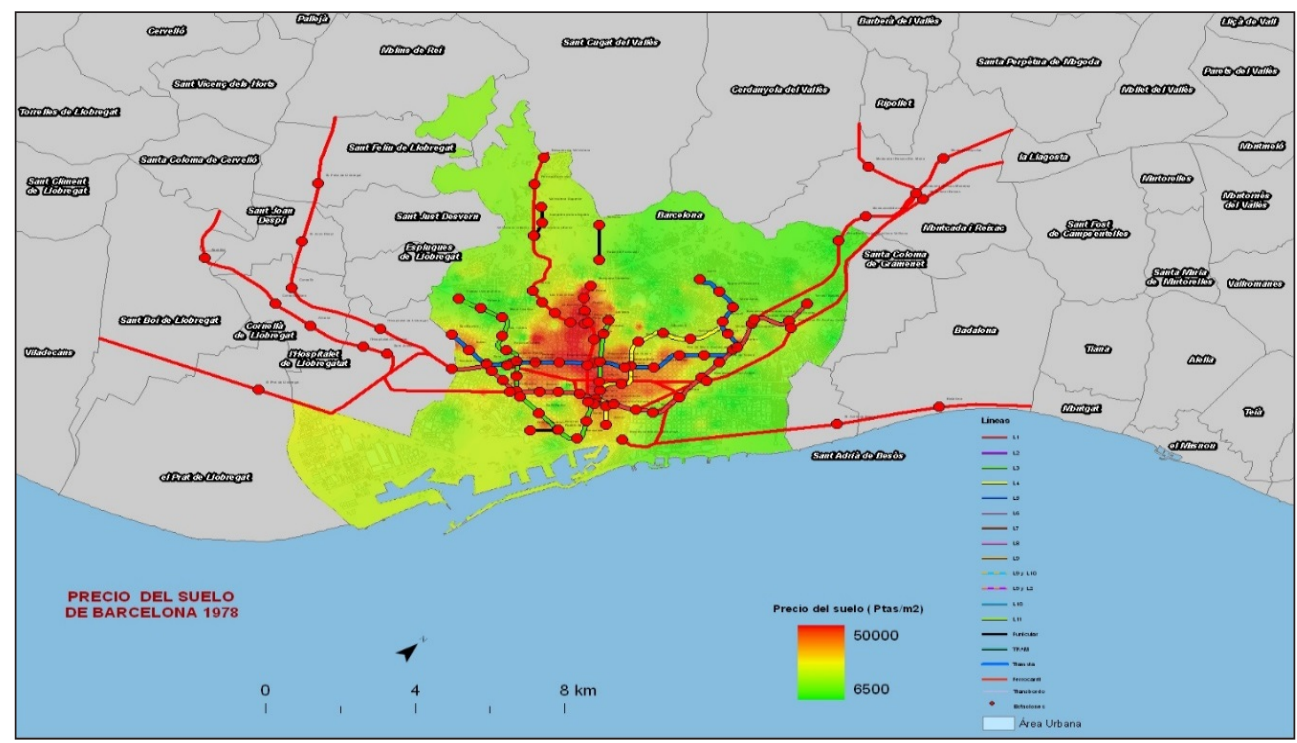

Fuente: elaboración propia a partir de Maragall. P. (1979).

El precio mínimo de la vivienda siguió un proceso similar. De un mínimo de 50 pesetas por $\mathrm{m}^{2}$ que existía en 1951 , se pasó a un mínimo de 6.500 pesetas en 1978, siendo también el salto cuantitativo total más brusco , el realizado entre 1972 y 1978 (2.000 pesetas por $\mathrm{m}^{2}$, frente a 6.500 pesetas por $\mathrm{m}^{2}$ ). Sin embargo, a nivel porcentual, el salto cuantitativo más prominente fue el producido entre 1960 y 1972, ya que se pasó de 100 pesetas por $\mathrm{m}^{2}$ a 2.000 pesetas por $\mathrm{m}^{2}$, es decir, se multiplicó por 20 el precio mínimo de la vivienda.

A este prolongado auge del precio de la vivienda se sumó el hecho de que las pautas de distribución del precio de la vivienda también variaron. En cada año del período analizado se observa una situación distinta. Se aprecian tres áreas diferenciadas en cada época, en función del precio de la vivienda. Existe una única área central con elevados precios de la vivienda. Esta área está rodeada de una zona de precio intermedio y, a su vez, ésta está rodeada de una zona de precio mínimo de la vivienda. El área de gran valor de la vivienda y el área de valor intermedio de la vivienda suelen ocupar una séptima parte del territorio municipal de Barcelona cada una, constituyendo aproximadamente un tercio del total de la superficie. Las otras dos terceras partes corresponden a las áreas de bajo precio de la 
vivienda. Esta proporción se mantiene de forma constante en los tres períodos temporales analizados. Por lo tanto, según esta estructura, es la evolución del área de mayor valor de la vivienda la que modifica el conjunto. Al variar de estructura las áreas de mayor valor, el resto de áreas se ajustaron a ella.

En 1951, el área central de mayor valor se ubicaba claramente entre las estaciones de Plaza Catalunya y Lesseps a través de toda la izquierda del Ensanche. Este área estaba perfectamente delimitada por una línea de tranvía que circundaba y delimitaba la zona señalada. Este área estaba totalmente integrada en las redes de metro y tranvía, lo que evidencia una relación directa entre infraestructura de transporte y precio de la vivienda. El resto de áreas servidas por las infraestructuras ferro-viarias poseían un valor intermedio y las áreas desprovistas de infraestructuras ferro-viarias poseían un bajo precio de la vivienda.

Entre 1960 y 1972, la situación mantuvo su esquema fundamental, aunque el área de elevado valor de la vivienda se amplió hacia el oeste, norte y sur del Ensanche.

Sin embargo, en 1978 la situación varió. Entre 1960 y 1972 se procedió al desmantelamiento súbito del tranvía en Barcelona. Debido a la rapidez de dicha operación, los precios de la vivienda entre 1960 y 1972 se mantuvieron estables. Sin embargo en 1978 se dejaron notar las consecuencias de esta operación. Los precios de la vivienda se adaptaron al área central circunscrita por las líneas de metro y se repartió homogéneamente el precio de la vivienda a ambos lados del Ensanche entre la estación de Sants y la de Sagrada Família, y entre la estación de Catalunya y todo el norte del área urbana barcelonesa. El resto de zonas urbanas conectadas con las líneas ferro-viarias poseían un precio intermedio y las que no estaban conectadas poseían un precio bajo.

Se evidencia de esta manera que una variación en las infraestructuras de transporte comporta así mismo una variación en el precio de la vivienda. Por lo tanto, se concluye que el precio de la vivienda y los sistemas ferro-viarios son dos factores que se interrelacionan mutuamente.

\section{CONCLUSIONES}

Existe una clara relación entre la distribución de los equipamientos y la red ferroviaria. En el área central de Barcelona es donde se suelen aglomerar los equipamientos aunque también hay un gran número de éstos en las áreas centrales de los municipios periféricos del área metropolitana de Barcelona. Esta pauta de localización en las áreas centrales de los espacios urbanos es compartida por las infraestructuras de transporte ya que las áreas centrales de las principales áreas urbanas son aquellas que son más accesibles a la mayoría de la población debido a su alto grado de centralidad. Tanto las infraestructuras ferro-viarias, como los equipamientos, tienden a situarse en estas áreas. Se trata, por tanto, de una cuestión relacionada con la localización espacial ambiental común. De hecho, la ampliación de las redes ferro-viarias previstas para el año más allá del 2020 se ha planificado teniendo en cuenta la ubicación de los equipamientos, especialmente aquellos presentes en la periferia del área metropolitana barcelonesa. En este caso, son las infraestructuras de transporte las que han planificado su estructura en función de los equipamientos. Este hecho corrobora la teoría que afirma que el desarrollo urbano y el crecimiento de las infraestructuras de transporte poseen una dinámica de interdependencia. 
Por otra parte, el análisis de los centroides correspondientes al área urbana de Barcelona y al área de cobertura de las estaciones de la red ferro-viaria existente en cada momento histórico, constata que se ha producido un proceso paralelo entre la expansión urbana y la expansión de las redes ferro-viarias. La época de mayor disparidad entre el área urbana barcelonesa y la red ferro-viaria es la correspondiente a la Guerra Civil y a la posguerra. Este hecho es debido a que, en esa época, la falta de presupuesto disponible impidió la inversión en materia de infraestructuras. Sin embargo, ahora, los planes de ampliación de la red tienen en consideración la estructura urbana de Barcelona. Actualmente, se ha proyectado una ampliación de la red ferro-viaria, muy ambiciosa, en la que se prolonga la práctica totalidad de las líneas por todo el continuo urbano de Barcelona. Esto es posible debido a que el área urbana de Barcelona está bastante estabilizada en torno a los $150 \mathrm{~km}^{2}$. Se ha completado la colmatación del llano barcelonés y los condicionantes topográficos impiden, en gran medida, la ampliación urbana. Por ello, al existir un área urbana muy bien definida y delimitada, las infraestructuras pueden conformar un auténtico esqueleto que cruce toda el área de forma eficiente. Al mismo tiempo, al realizar un análisis técnico del conjunto de la red, se advierte el creciente aumento de las líneas y redes de transporte, su interrelación, cada vez más acusada, y una mayor densificación y conectividad del sistema ferro-viario. Estos datos corroboran la evolución conjunta de la red ferro-viaria y el espacio urbano de Barcelona.

Por último, es importante constatar que existe una clara vinculación entre precio de la vivienda y red ferro-viaria. Se han analizado diferentes períodos entre 1950 y 1980, en los que han existido unas importantes variaciones en el precio de la vivienda tanto cuantitativas como cualitativas. Las variaciones cuantitativas se produjeron porque el precio de la vivienda se multiplicó por 7 en apenas una década (entre 1960 y 1972). Las variaciones cualitativas se produjeron al modificarse los valores del precio de la vivienda, en función de las variaciones de la red ferro-viaria. En concreto, la supresión del tranvía y la ampliación del metro (1960 y 1978) produjo una serie de variaciones espaciales que indicaban que la estructura ferroviaria delimitaba las áreas de mayor valor residencial de Barcelona. Se constata, por tanto, la relación entre valor de la vivienda y estructura ferro-viaria.

\section{REFERENCIAS}

AGUIRRE NÚÑEZ, C. y MARMOLEJO DUARTE, C. (2010): "Hacia un método integrado de identificación de subcentros a escala municipal: un análisis para la región metropolitana de Barcelona". ACE. Architecture, Cyti and Environment, vol. 5 (13), 99-122.

ALCAIDE GONZÁLEZ, R. (2005): “El ferrocarril como elemento estructurador de la morfología urbana: el caso de Barcelona 1848-1900” en Scripta Nova. Revista electrónica de geografía y ciencias sociales, vol. IX, n. ${ }^{\circ} 194$ (65). Universidad de Barcelona. Disponible en http://www.ub.es/geocrit/sn/sn-194-65.htm

ALCAIDE GONZÁLEZ, R. (2010): El ferrocarril en Barcelona 1848-2010. Desarrollo, implicaciones urbanas y perspectivas para el siglo XXI. Director: Horacio Capel. Barcelona. Universitat de Barcelona. 
ALCALÁ, L. (2006): "Reflexiones sobre algunas estrategias urbanísticas en la ciudad de Barcelona durante el último cuarto del siglo XX". Cuaderno Urbano. Espacio, Cultura y Sociedad, $n^{\circ} 5,75-103$.

ALEGRET BURGUÉS, A. y CABRÉ i PUIG, E. (2008): "Valorar el suelo de forma sostenible". ACE, año III, $\mathrm{n}^{\circ} 6$.

ALEMANY, J. y MESTRE, J. (1986): Els transports a l'àrea de Barcelona. Diligències, tramvies, autobuses, metro. Barcelona. T.M.B.

ANDREU, M.; HUERTAS, G.; HUERTAS, J.M. y FABRE, J. (1997): La ciutat transportada: dos segles de transport col-lectiu al Server de Barcelona. Barcelona. Transports Metropolitans de Barcelona, DL.

ASENSIO RUIZ DE ALDA, F.J. (2000): Cambios en la forma urbana y demanda de transporte. Barcelona. Publicacions de la Universitat Autònoma de Barcelona.

BELlET, C.; ALONSO, P. y CASELlAS, A. (2010): "Infraestructuras de transporte y territorio. Los efectos estructurantes de la llegada del tren de alta velocidad en España.". Boletín de la Asociación de Geógrafos Españoles, n 52, 143-163.

BERNAT FALOMIR, J. (2004): "Los cambios en la estructura de valores en el territorio. El ejemplo de Barcelona". CT: Catastro, n. ${ }^{\circ}$ 51, 41-58. BUCHANAN, C. (1973): El tráfico en las ciudades. Madrid. Tecnos, D.L.

BUSQUETS GRAU, J. (1992): Barcelona: evolución urbanística de una ciudad compacta. Madrid. MAPFRE, D.L.

CAPEL, H. (2011): Los ferro-carriles en la ciudad. Redes técnicas y configuración del espacio urbano. Madrid. Fundación de los Ferrocarriles Españoles.

CANDEL, F. y CASAMINAS, M. (1994): Barcelona i el ferrocarril. RENFE.

DELGADO VIÑAS, C. (2010): "Entre el puerto y la estación. La influencia de las infraestructuras de transporte en la morfología de las ciudades portuarias españolas (18481936)" en Scripta Nova. Revista Electrónica de Geografía y Ciencias Sociales, vol. $\mathrm{XIV}, \mathrm{n}^{\circ} 330$. Universidad de Barcelona. Disponible en http://www.ub.es/geocrit/sn/ sn-330.htm

FEBRÉS, X.; MISERACHS, X. y SALA, M. (1991): Metros y metrópolis. Barcelona. Edicion Ferrocarril Metropolità de Barcelona.

GALLEGOS, G.A. (2010): Análisis de las actividades urbanas y su impacto en la movilidad de Barcelona. Director: Carlos Marmolejo. CPSV. Universitat Politècnica de Barcelona. Disponible en http://www-cpsv.upc.es/tesis/TM10presentacio_ggallegos.pdf

GARCÍA CATALÁ, R. (2010): "Crecimiento urbano y el modelo de ciudad". ACE. Architecture, Cyti and Environment, vol. 4 (12), 159-168.

GARCÍA MARTÍNEZ, C. (2009): Impacto de las estrategias de ubicación y oferta de los centros comerciales sobre las pautas de la movilidad de la Región Metropolitana de Barcelona. Director: Pere Espelt Lleonart. Universitat Politècnica de Catalunya. Departament d'Infraestructura del Transport i del Territori. 2009. Disponible en http:// upcommons.upc.edu/pfc/handle/2099.1/10126

GÓMEZ GAMBOA, D.P. (2011): Efectos de grandes transformaciones urbanas en el cambio de usos de suelo: el caso de Barcelona y su entorno a partir de los años cin- 
cuenta. Director: Josep Roca Cladera y Bahaaeddin Alhaddad. Universitat Politècnica de Catalunya. Departament de Construccions Arquitectòniques I. 2011. Disponible en http://upcommons.upc.edu/pfc/handle/2099.1/12785

HERCE VALLEJO, M. y MIRÓ FARRERONS, J. (2002): El soporte infraestructural de la ciudad. Barcelona. UPC.

JANÉ SOLÁ, J. (1972): El transporte colectivo urbano en España. Barcelona. Ariel.

JIMÉNEZ GARCÍA, M. (1986): Ferrocarril y desarrollo urbano. Santander. Universidad de Cantabria.

JULIÀ SORT, J. (2005): Redes Metropolitanas. Metropolitan Networks. Barcelona. Editorial Gustavo Gili.

LLUCH, E. (1972): Preus del sòl a Catalunya. Barcelona. Servei d'Estudis de Banca Catalana.

MARAGALL, P. (1979): Els preus del sòl. Director: Josep M. Vegara Carrió. Universitat Autònoma de Barcelona. Disponible en http://www.tesisenred.net/handle/10803/3977

MIRALLES GUASCH, C. (1996): Transport i ciutat. Una reflexió sobre la Barcelona contemporània . Director: Antoni Tulla Pujol. Universitat Autònoma de Barcelona. Disponible en http://www.tesisenred.net/handle/10803/4986

MUMFORD, L. (1966): La ciudad en la historia: sus orígenes, transformaciones y perspectivas. Buenos Aires. Infinito.

PARCERISA, J. y RUBERT DE VENTÓS, M. ( 2001): Metro. Barcelona. UPC.

PASCUAL PEAGUDA, A. (2009): Análisis y evolución histórica de los nudos viarios en Barcelona. Director: Francesc Magrinyà Torner. Universitat Politècnica de Catalunya. Disponible en http://upcommons.upc.edu/pfc/handle/2099.1/10118

PÉREZ FERNÁNDEZ, F. (1994): "La integración del ferrocarril en la ciudad". Revista de Obras Públicas, no 3.331, año 141, 79-89.

POZUETA ECHAVARRI, J. (2000): “Movilidad y planeamiento sostenible: Hacia una consideración inteligente del transporte y la movilidad en el planeamiento y en el diseño urbano". Cuadernos de Investigación Urbanística. no 30, 1-109.

REYES SCHADE, E. (2011): El espacio público en la inserción del tranvía. Director: Antoni Remesar Betlloch. Universitat de Barcelona. Disponible en http://webcache. googleusercontent.com/search?q=cache:-283LGL4uqQJ:diposit.ub.edu/dspace/bitstream/2445/21002/1/01_reyes_schade.pdf+EL+ESPACIO+PUBLICO+EN+LA+INSE RCION+DEL+TRANVIA\& $\mathrm{cd}=1 \& \mathrm{hl}=\mathrm{es} \& \mathrm{ct}=\mathrm{clnk} \& \mathrm{gl}=\mathrm{es}$

ROCA i CLADERA, J. (1986): Los precios del suelo en el ámbito metropolitano. Barcelona. Corporació Metropolitana, Assessoria de Comunicació i Relacions, D.L.

SALAS, R. (2001): "Evolución de la red ferroviaria e influencia de ésta sobre el crcimiento urbano en Barcelona y su área metropolitana". en Congreso de Historia Ferroviaria, Aranjuez. Disponible en http://www.docutren.com/archivos/aranjuez/pdf/08.pdf SEGUÍ PONS, J.M. y PETRUS BEY, J.M. (1991): Geografía de redes y sistemas de transporte. Síntesis. Madrid.

SOLÁ MORALES i RUBIÓ, M. (1997): Las formas de crecimiento urbano. Barcelona. UPC. 
TARAVILLA RODRÍGUEZ, M. (2010): Prognosis dels impactes socials i urbanístics de la "unió del trambesòs amb el trambaix". Director: Míriam Villares Junyent y Rosa Junyent Comas. Universitat Politècnica de Catalunya.2010. Disponible en http:// upcommons.upc.edu/pfc/handle/2099.1/12590

VALLÈS FERRER, J. y HAP DUBOIS, E. (1978): El transporte en las grandes ciudades. Sevilla. Universidad de Sevilla.

XALABARDER AULET, M. (1999): "La avenida de la luz, una calle subterránea en Barcelona”. Estudios Geográficos, nº 236, 487-512. 
